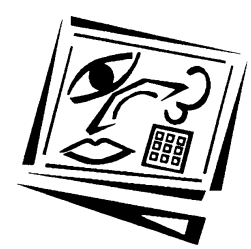

\title{
Towards a communicative model of collaborative web-mediated learning
}

\author{
Dubravka Cecez-Kecmanovic and Carolyn Webb
} University of Western Sydney

\begin{abstract}
This paper reports research investigating web-mediated collaborative learning as a social interaction process from a critical theory perspective. A communicative model of collaborative learning is proposed to help instructors analyse and improve the practice of collaborative learning. The model can also be used as a methodological instrument for inquiry into web-mediated collaborative learning.
\end{abstract}

\section{Introduction}

Collaborative learning evolved from the works of Piaget (1926) and Vygotsky (1978) who contend that learning occurs more effectively through interpersonal interactions in a cooperative rather than competitive context. Compared to individual learning, research on traditional face to face collaborative learning revealed numerous benefits: better performance, better motivation, higher test scores and level of achievement, development of high level thinking skills, higher student satisfaction, etc. (Johnson et al., 1981; Dansereau, 1983; Slavin, 1987; Sharon, 1990). More recent research on computer supported collaborative learning has confirmed these benefits and has shown that they can be enhanced even further through adequate technological support (eg. Alavi, 1994; Hiltz, 1995; Huynh, 1999). While these are important and very encouraging results, a deeper understanding of the 'inside' of the collaborative learning processes is still missing. The relative paucity of reported inquiry into the nature of collaborative learning within computer supported learning situations, we believe, has militated against the wider uptake of collaborative learning pedagogies.

A key feature that distinguishes collaborative learning from individual and competitive learning is its social nature. Students interact and share their ideas to improve both their individual and mutual understanding, to 
solve problems cooperatively, and to complete their common tasks. Their learning takes place in a particular social milieu and, apart from developing their intellectual skills, involves developing their social skills and establishing social interrelationships. Their social interactions are mediated through language, or more precisely through linguistic acts, with the aim of reaching understanding and achieving aims (Klein and Huynh, 1999). Therefore we argue that the analysis of language acts and communicative practices involved in collaborative learning is a promising path towards deeper insight into collaborative learning processes.

The research presented here focuses on collaborative learning as a social interaction process, with the aim of gaining a deeper insight into the complex and largely uninvestigated communicative practices of webmediated collaborative learning (Cecez-Kecmanovic and Webb, 1999; Cecez-Kecmanovic et al., 1999). By enabling social interactions via an electronic medium, unrestrained by space, time and pace, web technologies actually expand and transform the social interaction space of collaborative learning. Students can work together, achieve shared understanding, and cooperatively solve problems in the new webmediated environment. We aim to go beyond the evident, and 'look and see' what is happening in actual flows of conversations in web-mediated collaborative learning by applying Habermas' (1984, 1987) theory of communicative action. This paper introduces a social theoretical foundation of collaborative learning and proposes a communicative model of collaborative learning as a pedagogical tool for improving the practice of collaborative learning as well as a methodological instrument for inquiry into web-mediated collaborative learning.

In the following section we first explore the meaning of success in collaborative learning processes and propose the degree of satisfaction of the ideal learning situation as a measure of success. In section 3 we briefly introduce the notion of linguistic acts as social interaction mechanisms building up collaborative learning processes. We then present a typology of these linguistic acts in section 4 . In section 5 we introduce another dimension of social interactions: students' orientation (to learning, to achieving ends or to self presentation). By integrating the two dimensions in section 6 we propose a communicative model of collaborative learning and indicate how it can be used in analysing and assessing the success of concrete collaborative learning processes. We conclude by summarising possible implications of the communicative model of collaborative learning on both practical pedagogy and empirical research in webmediated environments. 


\section{Successful collaborative learning}

Learning effectiveness has been traditionally measured in terms of performance, self efficacy and satisfaction (Ahmad et al. 1998). Huynh (1999) rightly points to the insufficiency of these measures in collaborative learning situations and suggests additional measures such as reaching common understanding, building team consensus, achieving critical reflection and self realisation, emancipation from constraints etc. The underlying problem here is understanding of the social interaction nature of collaborative learning and the meaning of success in collaborative learning. We propose here a new concept of success in collaborative learning measured as the degree of achievement of the ideal learning situation.

The concept of ideal learning situation is defined here as an instantiation of Habermas' concept of ideal speech situation in the context of collaborative learning. Similar to the conditions of an ideal speech situation we define the conditions of the ideal learning situation as a communicative practice free from any kind of distortion, any form of coercion and ideology, that "excludes all force ... except the force of the better argument" (Habermas, 1984 , p. 25). All students exercise unrestricted rights to participate and contribute. The relevance of this concept to the discursive practice of collaborative learning is not to describe an ideal, never attainable condition, but rather to elucidate that for the students to engage in a meaningful communication leading to learning, the conditions of the ideal learning situation have to be satisfied to a sufficient degree. Although there is no measure of satisfaction of the ideal speech conditions, Habermas maintains that participants in any practical discourse situation are aware of the "degree of satisfaction" of these conditions. Within this theoretical perspective the success of a collaborative learning process can be conceptualised as the degree of satisfaction of ideal learning conditions. In other words the higher the degree of violation of the conditions for an ideal learning situation, the less likely it is that the group of students will accomplish successful collaborative learning.

The impact of web-mediated collaborative learning can be explored from the perspective of ideal learning conditions. By providing electronic means for communication, web-based technologies in fact extend the communicative space of learners. Particular characteristics of this new extended communicative space that affects learning conditions are: permanent recording of student interactions, including flow of interactions in a period of time, either with (asynchronous interaction) or without delays (synchronous interaction), and any time any place access to these records by participants, learners and instructors alike. Consequently, this 
electronic communicative space creates a collaborative learning environment that challenges the limits of interactions experienced in face to face situations. From the perspective of ideal learning situations, the most important challenge comes from free and equal access by all participants to the learning process, equal opportunity and unrestricted contributions to collaborative learning, at least from a technical point of view. While social forms of communicative distortion can still be successfully practised, their presence is more visible, thereby making the participants more aware of the actual degree of satisfaction of ideal learning conditions. Moreover, a web-mediated collaborative learning environment is more amenable to the analysis of communicative practices based on computer evidence (as a by product of the learning process) which enables post factum assessment of the degree of satisfaction of ideal learning conditions.

Another important implication of conceiving collaborative learning as social interaction is its volitional character. Collaborative learning requires both students' and instructors' predilection to collaboration that involves developing mutual understanding, cooperation, co-creation of knowledge, and a communicatively accomplished learning. Therefore learning through a collaborative process cannot be forced upon or induced through outside forces: it has to be internally created, mutually accepted as valid and valuable, and enacted by students and instructors. This again reminds us that by introducing web-mediated learning environments, we cannot directly affect learning but rather learning conditions, seeking to get closer to an ideal learning situation.

In order to explore further the social interaction nature of collaborative learning and the conditions of the ideal learning situation, we shall first investigate the linguistic acts that constitute collaborative learning processes.

\section{Linguistic acts and collaborative learning}

Collaborative learning is primarily mediated by language. Acts of communication or language acts function as social interaction mechanisms building up collaborative learning processes. According to speech act theory (Searle, 1979; Austin, 1962), a minimal unit of human communi-cation is not a sentence but a performance of a particular kind of language acts, such as assertions, declaratives, promises, orders or requests. Apart from a literal meaning a speech act has its performative meaning: that is, not what is said but what is done by saying. Habermas (1984) criticises Austin's and 
Searle's approach and develops his version of speech act theory by understanding social interactions as coordinated by speech acts.

In our application of speech act theory we perceive speech or linguistic acts as constituting elements of collaborative learning. We make here a distinction between language acts and the context of collaborative learning interactions that they constitute. While we shall not use either Searle's classification or Habermas' re-classification of speech acts, we shall attempt to investigate and classify language acts as constitutive of collaborative learning process. Once we are able to specify the types of language acts that constitute collaborative learning and understand conditions for their successful deployment in collaborative learning situations, we shall be in a position to improve conditions and achieve more successful collaborative learning.

\section{The types of linguistic acts constituting collaborative learning processes}

Our analysis in this section focuses on linguistic acts employed in collaborative learning processes. What are the types of linguistic acts through which students construct (constitute) collaborative learning? We are not seeking to analyse the substantive meaning of the utterances but rather to identify types of linguistic acts responsible for establishing, maintaining and carrying out collaborative learning processes.

Students exchange linguistic acts in order to explore the subject matter, that is express claims and supporting arguments, seek clarification and additional justification, express opposing claims and counter arguments, judge the arguments provided, and thereby share understanding and construct knowledge in the subject matter domain. They use other types of acts to refer to norms and rules assumed to govern their interaction and the process of collaborative learning itself. They may, for instance, raise the issue of their rights to speak and present their ideas, views or positions openly irrespective of the fact that these may differ from the established truth, instructors' opinion, textbook etc. They may also dispute some norms or rules, provide arguments to change them and seek agreement from other students and instructors. In all these cases students are referring to a particular kind of knowledge from their micro social world, defined by norms and rules. Students use yet another type of language acts to express their individual expectations, attitudes and feelings about the learning process and their satisfaction with learning. 
Clearly different types of language acts, referring to different domains of knowledge, are used to do different things: explore and deal with claims related to subject matter; regulate the conduct of interactions and establish interpersonal relations in the learning process; as well as express themselves and shape both their individual and collective sense of self. Often, however, the same linguistic act may have multiple performative meanings.

We are proposing here the following typology of collaborative learning (linguistic) acts according to the domain of knowledge1:

1. Linguistic acts addressing (relating to) the subject matter and the topic of discussion

- seeking understanding either by sharing, strategically expressing or imposing believes

- raising claims, providing arguments, reasons, grounds

- disputing claims, providing counter arguments and grounds

- asking clarification, interpreting meaning of expressions, etc.

2. Linguistic acts addressing norms and rules governing the process of collaborative learning

- organising and directing the process of interaction

- establishing or disputing rules of conduct and speech (normative regulation of the process of interaction)

- claiming that some norms or rules are violated (acts that relate practical discourse to accepted norms or rules)

3. Linguistic acts addressing personal experiences, desires and feelings

- expressing personal views about, assessment of or expectations from the learning process

- expressing an individual reflexive relation to the learning process

- expressing personal attitudes to cooperation and relationships with others (heedful interrelating, intention to influence others, wish to dominate and exert control, etc.)

1 These knowledge domains remotely correspond to the Habermas' three world concept: "the objective world (as the totality of all entities about which true statements are possible); the social world (as the totality of all legitimately regulated interpersonal relations); and the subjective world (as the totality of the experiences of the speaker to which he has privileged access)" (1984, p. 100). 
Each of these types of linguistic acts, corresponding to three knowledge domains has specific roles in constituting and maintaining collaborative learning process.

\section{Students' orientation in collaborative learning processes}

Students linguistic acts cannot be fully explained by their reference to a type of knowledge only. To understand the performative meaning, what is being done by saying, we have to attend to students' orientation in the collaborative learning process. Guided by the idea of action orientation (as one of the defining dimensions of Habermas' communicative action types2), we propose the following distinction of dominant students' orientation in the learning processes:

1. Orientation to learning - manifested as a wish to know, to interact with others to increase mutual understanding, to explore and experiment, to discuss and test new ideas, concepts, etc.

2. Orientation to achieving an end - manifested as an intention to succeed eg to get a pass or a good mark, or to get the best mark in the class, to beat another student, etc.

3. Orientation to self presentation manifested as achieving an impression on others, portraying a particular image of self. 3

It has to be emphasised here that these are idealised types of students' orientation. No doubt all students aim to complete a course successfully, while placing more or less emphases on what they will actually learn, what their final mark will be and what impression they will make on other fellow students and instructors. However, the students' dominant orientation is what largely determines their attitudes and communicative behaviour and thus impacts on the learning process.

2 Habermas defines instrumental, strategic and dramaturgical action as those oriented to achieving success, and normatively regulated action and communicative action as ones oriented to reaching understanding (1984).

3 Referring to purposive-instrumental rationality, that Habermas (1984) so eloquently criticises, and communicative rationality, that he no less eloquently advocates, we maintain that, in the context of interactions within collaborative learning process, two orientations - to achieve ends and self-representation exemplify purposiveinstrumental rationality, while learning orientation exemplifies communicative rationality. 
Generally any type of linguistic act from the above typology can be used within each of the three orientations. In fact one would fully understand a meaning of the linguistic act if one knows the learner's orientation within which it has been uttered.

Consider for instance a student's disagreement with another student's claim in a debate. A student oriented to learning would do this if he is convinced that the other student's claim is wrong and would thus try to raise a counter claim and resolve the disputed claim cooperatively, seeking to reach mutual understanding with other students. On the other hand, a student predominantly oriented to achieving an end, such as being favourably assessed by the instructor, may express disagreement with another student's claim, even ignore the arguments provided to support the claim, in order to demonstrate his superior knowledge, his ability to argue his case, without actually seeking mutual understanding in the group. In the case of a student's disagreement with another student's claim just for the sake of opposing it or opposing him/her, we recognise a self presentation orientation.

\section{Communicative model of collaborative learning}

A collaborative learning situation can now be analysed along two dimensions:
A. Knowledge domains of linguistic acts - using the proposed typology of language acts, and
B. Learners' dominant orientation: to leaning, achieving ends or self presentation

As we have seen it is not enough to understand the meaning of a particular linguistic act per se: it has to be grasped and interpreted within the dominant orientation of the learner. Accordingly the analysis of a concrete learning process solely from the aspect of learner's orientation is equally incomplete. Therefore communicative analysis of interactions in a collaborative learning process has to be integrative involving both dimensions.

The communicative model of collaborative learning (CMCL), presented in Table 1, integrates the two dimensions of communicative analysis into a comprehensive model. Within such a model we can investigate an individual linguistic act in terms of what it refers to and the same time how it contributes, what it does (in a flow of linguistic acts of a conversation) to the construction and maintenance of collaborative learning process. Although, for instance, a certain linguistic act may be of 
the same type eg. disputing (assumed or accepted) norms and rules, what it actually produces depends on the student's orientation. A student oriented to learning may dispute a norm seeking mutual understanding with other students and cooperative resolution; a student oriented to achieving a good mark may dispute a norm if it does not suit her particular goals, seeking to change it without being much concerned about others; a student oriented to self presentation may dispute a norm for the sake of presenting himself in a particular way, as a certain type of persona, thus maintaining his image among the participants. Types of linguistic acts listed in each of the nine cells in Table 1 are derived from two case studies of collaborative learning enabled by WebCT Forum (CecezKecmanovic et al., 1999).

Furthermore by analysing students' interaction within the framework of $\mathrm{CMCL}$, we can assess to what extent conditions of the ideal learning situation are met. We assume that these conditions are improving from the bottom level of self presentation orientation towards the top level of learning orientation. Distortion of communication by a student oriented to self presentation may for example involve ignorance of other students' claims and over-insistence on his personal views and opinions; disregard for other students' interests, wishes and desires; instrumentalising trust and relationships among group members, and potentially the learning situation (perceived as a stage for personal promotion). Other kinds of distortion by a student oriented to achieving goals include language acts aiming at strategic influence on other students' opinions and beliefs, pushing, imposing things on other students in the group; maintaining relationships with other students to serve his particular goal, etc. The presence of these communicative distortions usually disrupts collaborative learning processes and, if persistent and severe, may cause its complete failure.

On the other hand, students genuinely oriented to learning, while also raising claims and counter claims, disputing others' opinions and arguing their views, do so in a cooperative way, 'guided by the force of the better argument', trying to establish mutual understanding and respect for others with different views. Orientation to learning is a fertile soil for establishing an ideal learning situation. 


\begin{tabular}{|c|c|c|c|c|c|c|c|c|c|}
\hline 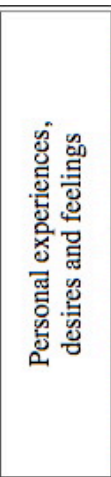 & 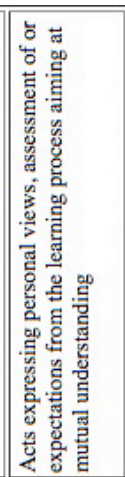 & 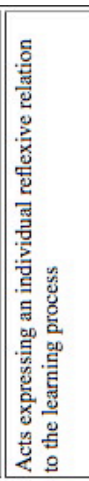 & 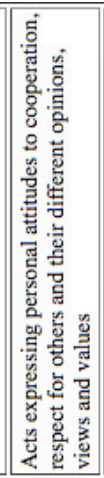 & 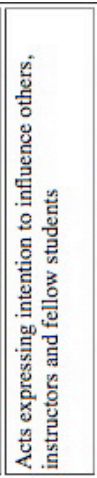 & 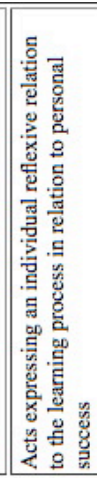 & 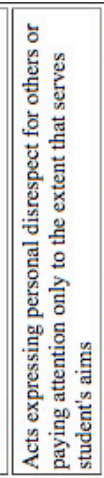 & 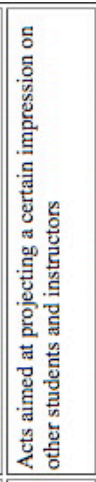 & 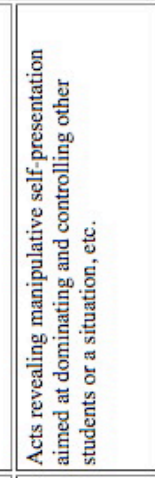 & 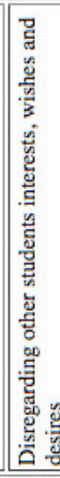 \\
\hline 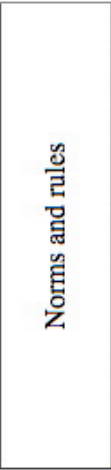 & 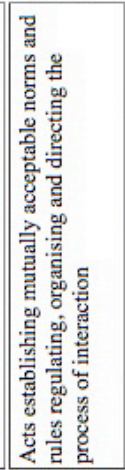 & 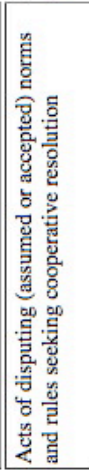 & 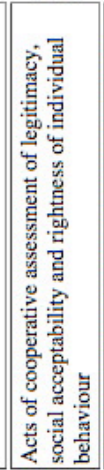 & 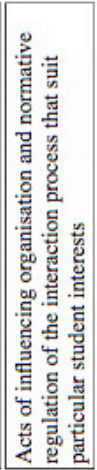 & 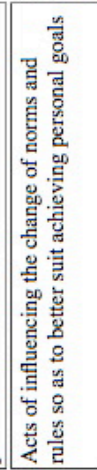 & 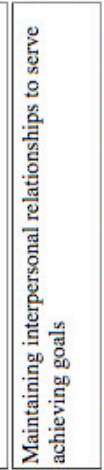 & 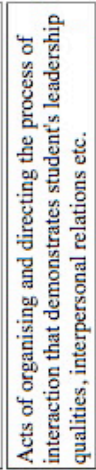 & 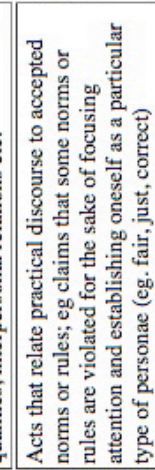 & \\
\hline 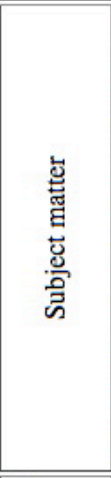 & 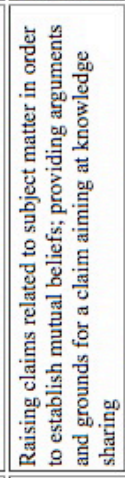 & 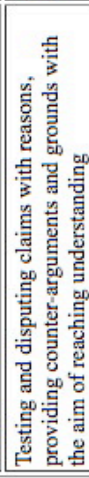 & 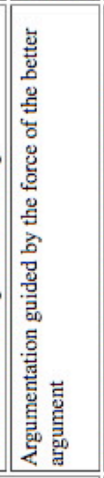 & 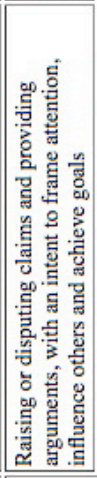 & 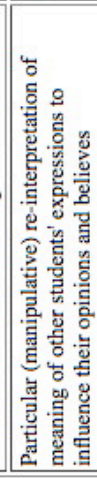 & & 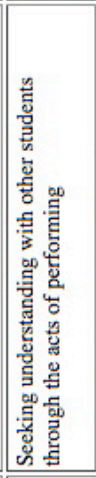 & 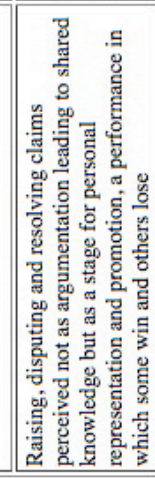 & 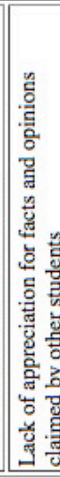 \\
\hline 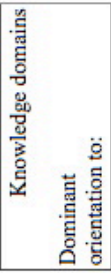 & $\begin{array}{l}\text { 眳 } \\
\text { 怘 }\end{array}$ & & & 。 & & & & & \\
\hline
\end{tabular}


In any concrete learning situation, however, we cannot expect anything approximating an ideal learning situation nor even a 'natural' evolution towards such a situation. Rather we have to be sensitive to all kinds of distortions of communications that take place, either in an overt or covert way, that prevent cooperative learning, knowledge sharing and construction, trust building, self realisation and emancipation of participants. This is where CMCL can help us and guide us to look carefully at the ways students interact, exchange linguistic acts and construct learning situations. This model can lead us see beyond the words and comprehend the deeds. By virtue of its facilitating and mediating role, web technology provides us with transcripts of communication and thereby the data we need to analyse the learning processes. These transcripts are like a footprint of the collaborative learning process, a footprint which is not so visible when the interactions occur face to face.

\section{Concluding remarks - implications of $\mathrm{CMCL}$}

This paper adopts a critical approach to collaborative learning and proposes a communicative model of collaborative learning built upon Habermas' theory of communicative action. CMCL is conceived as both a pedagogical tool for practical application and a methodological instrument for empirical investigation of collaborative learning, especially in webbased environments. CMCL enables exploration of the actual flows of linguistic acts, the way students use linguistic acts to shape attention, beliefs, attitudes, mutual relationships, and sense of self and of themselves as a group. It further enables the interpretation of meaning of these language acts not only in a phenomenological sense but also in a pragmatic sense: revealing what they produce in a learning situation, how they construct (or prevent) collaborative learning, cooperative meaningmaking, knowledge sharing and co-creation.

As praxis, CMCL links the practical pedagogical issues of students' interaction in a collaborative learning situation with the theoretical framework of communicative interaction. By providing a pedagogical tool for the analysis of concrete collaborative learning, CMCL is immediately practical, enabling us to monitor actual communicative practices and collaborative learning conditions, including collaborative accomplishments of learners. As instructors we can explore possible strategies to facilitate collaborative learning processes, assess and improve collaborative learning conditions. 
As a methodological instrument CMCL opens a new way of investigating web-mediated collaborative learning. It fosters a critical analysis of communicative practices in learning situations aiming to discover subtle ways of distorting communication and disabling ideal learning conditions. As a result the critical approach and CMCL may have a significant impact on research into collaborative learning, especially web-mediated.

The critical approach, as this brief presentation of CMCL has shown, teaches us that we cannot assume that by providing technologically advanced environments such as web-mediated group work and discussion spaces, and instructing students about the task, purpose of group work and norms of behaviour, successful collaborative learning will naturally take place. It warns us that we must be critical about the actual degree of satisfaction of ideal learning conditions in any concrete learning situation, attentive to the communicative needs of learners, and sensitive to subtle forms of communicative distortion and coercion that prevent equal participation, self fulfilment and emancipation of individual students. For if we do understand these issues we shall be better facilitators of collaborative learning situations, more conscious designers of webmediated collaborative learning environments and more ethical researchers of collaborative learning. The application and further development of CMCL can have significant implications for both practical pedagogy and empirical research on collaborative learning.

\section{References}

Ahmad, R., Piccoli, G., \& Ives, B. (1998). Effectiveness of virtual learning environments in basic skills business education: a field study in progress. Proceedings of ICIS'98, Helsinki, Finland, 352-357.

Alavi, M. (1994). Computer-mediated collaborative learning: An empirical evaluation. MIS Quarterly, 18, 2, 159-174.

Austin, J.L. (1962). How to Do Things With Words. Harvard University Press, Cambridge, MA.

Cecez-Kecmanovic, D. \& Webb, C. (1999). A critical inquiry into web-mediated collaborative learning, In A.K. Aggarwal (Ed), Web-based Learning: Opportunities and Challenges. IDEA Group Publishing, Hershey, PA.

Cecez-Kecmanovic, D., Webb, C. \& Tayler, P. (1999). Being flexible by being WISE two case studies of web-based teaching and learning. In M. Khosrowpour (Ed), Managing Information Technology Resources in Organizations in the Next Millennium. IDEA Group Publishing, Hershey, PA.

Dansereau, D. F. (1983). Cooperative Learning: Impact on Acquisition of Knowledge and Skills (Report No.341).US Army Research Institute for the Behavioural and Social Sciences, Abilene, TX. 
Habermas, J. (1984). The Theory of Communicative Action - Reason And The Rationalisation of Society (Vol I). Beacon Press, Boston, MA.

Habermas, J. (1987). The Theory of Communicative Action - The Critique of Functionalist Reason (Vol II). Beacon Press, Boston, MA.

Hiltz, S.R. (1995). The Virtual Classroom: Learning Without Limits via Computer Networks. Ablex Publishing Corp., New Jersey.

Huynh, M.Q. (1999). A critical study of computer-supported collaborative learning. Unpublished PhD, SUNY Binghamton, New York.

Johnson, D. W., Maruyama, G., Johnson, R. T., Nelson, D., \& Skon, L. (1981). Effect of cooperative, competitive, and individualistic goal structures on achievement: A meta analysis. Psychological Bulletin, 89, 47-61.

Klein, H.K. \& Huynh, M.Q. (1999). The potential of the language action perspective in ethnographic analysis. School of Management, SUNY Binghamton, New York.

Piaget, J. (1926). The Language and Thought of a Child. Routledge \& Kegan Paul, London.

Searle, J.R. (1979). Expression and Meaning. Cambridge University Press, Cambridge.

Sharon, S. (Ed.) (1990). Cooperative Learning: Theory and Research. Praege, New York

Slavin, R.E. (1987). Cooperative Learning: Student Teams. National Educational Association, Washington.

Vygotsky, L.S. (1978). Mind in Society: The Development of Higher Psychological Processes. Harvard University Press, Cambridge, MA.

Dubravka Cecez-Kecmanovic

IS-KOMO Research Group, Faculty of Management

University of Western Sydney

Locked Bag \#1 Richmond NSW 2753 Australia

Tel: +61 298524157 Fax: +61 298524185

Email: Dubravka@uws.edu.au

Carolyn Webb

Centre for Higher Education Development

University of Western Sydney

Locked Bag \#1 Richmond NSW 2753 Australia

Tel: +61 245701337 Fax: +61245701606

Email: Ca.Webb@uws.edu.au 